\title{
Biosorption of Acid Yellow by Spent Brewery Grains in a Batch System: Equilibrium and Kinetic Modelling
}

\author{
V.Jaikumar \\ Department of Chemical Engineering, A.C.Tech. Campus \\ Anna University Chennai, Chennai 600025, INDIA \\ Tel: 91-44-2220-3536 E-mail: jaikumar_phd@yahoo.com \\ V Ramamurthi (Corresponding author) \\ Department of Chemical Engineering, A.C.Tech. Campus \\ Anna University Chennai, Chennai 600025, INDIA \\ Tel: 91-44-2220-3523 E-mail: vramamurthi@yahoo.co.in
}

The research is financed by Council of Scientific and Industrial Research (CSIR), New Delhi, India, grant number CSIR Lr. No. 9/468(371)/2007-EMR-1 dated 30.03.2007.

\begin{abstract}
Biosorption of Acid Yellow (AY17) a monoazo acid dye currently used in textile and dyeing industries was investigated using Spent Brewery Grains (SBG) a brewing industry waste in a batch system with respect to initial $\mathrm{pH}$, temperature, initial dye concentration, biosorbent dosage, and contact time. The biomass exhibited the highest dye uptake capacity at $303 \mathrm{~K}$, initial $\mathrm{pH}$ value of 2 , the initial dye concentration of $150 \mathrm{mg} / \mathrm{L}$, biosorbent dosage of $0.5 \mathrm{~g}$ and contact time of 40 min. The extent of dye removal increased with increase in time, biosorbent dosage and decreased with increase in temperature. The equilibrium sorption capacity of the biomass increased on increasing the initial dye concentration up to $150 \mathrm{mg} / \mathrm{L}$ and then started decreasing in the studied concentration up to $600 \mathrm{mg} / \mathrm{L}$. The experimental results has shown that the acidic $\mathrm{pH}$ favours the biosorption. Langmuir and Freundlich adsorption model is used for the mathematical description of the biosorption equilibrium and isotherm constants are evaluated at different temperatures. Equilibrium data fitted very well to the Freundlich model in the studied concentration $(25-600 \mathrm{mg} / \mathrm{L})$ and temperature (303-323 K) ranges. The pseudo first- and second-order kinetic models were also applied to the experimental data. The results indicated that the dye uptake process followed the pseudo second-order rate expression and adsorption rate constants increased with increasing concentration.
\end{abstract}

Keywords: Biosorption, Acid yellow, Spent brewery grains, Isotherm, Kinetics

\section{Introduction}

Synthetic dyestuffs are used extensively in textile, paper, printing industries and dye houses. It is reported that there are over 100,000 commercially available dyes (Crini, 2006). The effluents from dyeing industries constitute one of the most problematic wastewaters to be treated not only for their high chemical and biological oxygen demands, suspended solids in toxic compounds but also for color, which is the first contaminant to be recognized by human eye. Dyes may significantly affect photosynthetic activity in aquatic life reducing light penetration and may also be toxic to some aquatic life due to the presence of aromatics, metals, chlorides, etc. Dyes usually have a synthetic origin and complex aromatic molecular structures which make them more stable and more difficult to biodegrade. Textile dyes are also designed to be resistant to fading by chemicals and light. They must also be resilient to both high temperatures and enzyme degradation resulting from detergent washing. For these reasons, degradation of dyes is typically a slow process.

Dye wastewater is usually treated by physical or chemical treatment processes. These include chemical coagulation/flocculation, precipitation, ozonation, adsorption, oxidation, ion exchange and photo degradation. Some of 
these techniques have shown to be effective, although they have limitations. Among these are: excess amount of chemical usage, or accumulation of concentrated sludge with disposal problems; expensive plant requirements and operational costs; lack of effective color reduction; and sensitivity to a variable wastewater input (Khattri \& Singh, 1998).

Adsorption has shown to be the most promising option for non-biodegradable dyes for the color removal from aqueous streams, activated carbons being the most common adsorbent for this process due to its effectiveness and versatility. Activated carbon is one of the most popular adsorbent used widely for adsorption studies. Activated carbon is usually obtained from materials with high carbon content and possessing a great adsorption capacity, which is mainly determined by their porous structure. Although activated carbon, in granular or powdered form has a good capacity for the adsorption of dyes, it suffers from a number of disadvantages. Activated carbon is quite expensive and the higher the quality the greater the cost. Both chemical and thermal regeneration of spent carbon is expensive, impractical on a large scale and produces additional effluent and results in considerable loss of the adsorbent. This has led many researchers to search for the use of cheap and efficient alternative materials such as Peat (McKay et al., 1981), Chitin (McKay et al., 1983), Silica (McKay, 1984), the hardwood sawdust (Asfour et al., 1985), Bagasse pith (McKay et al., 1987), Fly ash (Khare et al., 1987), Paddy straw (Deo, 1993), Rice husk (Lee \& Low, 1997), Slag (Ramakrishna \& Viraraghavan, 1997), Chitosan (Juang, et al., 1997), Palm fruit bunch (Nasser, 1997), and Bone char (Ko, et al., 2000).

The use of biomaterials as sorbents for the treatment of wastewaters will provide as a potential alternate to the conventional treatment methods. The process of uptake of solute using biomaterials (microbial cells), whether dead or alive, is known as biosorption. In the present investigation, the biomass SBG a brewery industry waste was used as biosorbent and its capacity to remove acid yellow an acidic (anionic) dye was evaluated. A survey of literature showed that no work has been done so far on dye removal process using SBG as biosorbent for the removal of acid yellow dye stuffs from their aqueous solutions. Acid yellow has wider applications, which include paper industry, leather industry, dyeing and textile industries etc.

The aim of this present work is to explore the possibility of utilizing SBG for the biosorptive removal of AY 17 dye from aqueous solution. The effect of factors such as temperature, initial dye concentration, biosorbent mass, contact time and $\mathrm{pH}$ of the solution was investigated. The kinetics of AY 17 adsorption onto SBG was analyzed by fitting to kinetics model. Experimental equilibrium data were fitted to Freundlich and Langmuir isotherm equation.

\section{Materials and Methods}

\subsection{Biosorbent}

Spent Brewery Grains, taken from Mohan breweries and distilleries Limited, Chennai, India, was suspended in 0.13M sulphuric acid solution $(20 \mathrm{~g}$ of SBG per $100 \mathrm{~mL}$ of acid solution) for one hour. Then it was filtered and the acid solution was discarded. The biomass was washed with distilled water many times until it is completely free from the acid and dried at $60^{\circ} \mathrm{C}$ for 24 hours. The dried biomass was ground and stored for further use in the experiments.

\subsection{Adsorbate}

The adsorbate AY 17 dye (C.I. $=18965$, Chemical formula $=\mathrm{C}_{16} \mathrm{H}_{10} \mathrm{Cl}_{2} \mathrm{~N}_{4} \mathrm{Na}_{2} \mathrm{O}_{7} \mathrm{~S}_{2}$

F W $=551.29$, nature = acid yellow 17) was supplied by Sigma-Aldrich Chemicals Ltd., India. The structure of AY 17 is given in Fig. 1. An accurately weighed quantity $(1 \mathrm{~g})$ of AY 17 was dissolved in double distilled water to prepare stock solution of $1000 \mathrm{mg} / \mathrm{L}$. Experimental solutions of the desired concentrations were prepared by dilution with double-distilled water.

\subsection{Analytical measurements}

The concentration of the dye AY 17 were determined using a UV-vis spectrophotometer (HITACHI U 2000, spectrophotometer) at a wavelength corresponding to the maximum absorbance of the dye $\left(\lambda_{\max }=401.5 \mathrm{~nm}\right)$. Calibration curves were plotted between absorbance and concentration of the dye solution.

\subsection{Batch experiments}

Batch experiments were conducted using $250 \mathrm{~mL}$ Erlenmeyer flasks to which $50 \mathrm{~mL}$ of dye containing waste water and biomass were added. These flasks were agitated in a temperature -controlled orbital shaker at a constant speed of 150 rpm to study the effect of important parameters like $\mathrm{pH}$, adsorbent dosage, initial dye concentration, contact time and temperature. Samples were withdrawn at appropriate time intervals and these samples were centrifuged (Research centrifuge Remi scientific work, India) at $4000 \mathrm{rpm}$. The supernatant was used for analysis of the residual dye concentration. The effect of $\mathrm{pH}$ on dye removal was studied over a $\mathrm{pH}$ range of 2-12. $\mathrm{pH}$ was adjusted by addition of dilute aqueous solutions of $0.1 \mathrm{~N} \mathrm{HCl}$ or $0.1 \mathrm{~N} \mathrm{NaOH}$. For the optimum amount of adsorbent per unit mass of adsorbate, a $50 \mathrm{~mL}$ dye solution was contacted with different amounts of SBG till equilibrium was attained. The kinetics of adsorption was determined by analyzing adsorptive uptake of the dye from the aqueous solution at different time 
intervals. The adsorption isotherm was found by agitating AY 17 solution of different concentrations with the known amount of SBG till the equilibrium was achieved. The effect of temperature on the sorption characteristics was investigated by determining the adsorption isotherms at 303, 313,323 K. Co (initial dye concentration) varied from 25 to $600 \mathrm{mg} / \mathrm{L}$.

\section{Results and Discussion}

\subsection{Effect of $p H$}

$\mathrm{pH}$ affects not only the biosorption capacity, but also the color of the dye solution and the solubility of some dyes (Fu \& Viraraghavan, 2001). Therefore, the $\mathrm{pH}$ value of the solution was an important controlling factor in the biosorption process, and the initial $\mathrm{pH}$ value of the solution has more influence than the final $\mathrm{pH}$ (Waranusantigul et al., 2003). The effect of initial pH on AY17 biosorption by SBG is shown in the Fig. 2. The maximum dye sorption occurred at pH 2 and the removal decreased thereafter. This may be due to high electrostatic attraction between the positively charged surface of the SBG and anionic dye AY 17. Acid dyes are also called as anionic dyes because of the negative electrical structure of the chromophore group. As the initial $\mathrm{pH}$ increases, the number of negatively charged sites on the biosorbent surfaces increases and the number of positively charged sites decreases. A negative surface charge does not favor the biosorption of dye anions due to electrostatic repulsion (Namasivayam \& Kavitha, 2002). In general, the acidic dye uptakes are much higher in acidic solutions than those in neutral and alkaline conditions (Chiou \& $\mathrm{Li}, 2002$ ).

\subsection{Effect of temperature}

Investigation of temperature effect on the biosorption of acidic dyes is very important in the real application of biosorption as various textile and other dye effluents are produced at relatively high temperatures. The biosorption of AY 17 on SBG was investigated as a function of temperature and maximum uptake value was obtained at $303 \mathrm{~K}$ as can be seen from Fig. 3. Adsorption decreased with further increase in temperature due to the decreased surface activity suggesting that biosorption between AY 17 and SBG was an exothermic process and the mechanism was mainly physical adsorption.

\subsection{Effect of biosorbent dosage}

The effect of biosorbent dosage on the removal of AY 17 by SBG at Co $=100 \mathrm{mg} / \mathrm{L}$ is shown in the Fig. 4. It can be seen that the AY 17 removal increases up to a certain limit and then it remains constant. The increase in the biosorption with the biosorbent dosage can be attributed to greater surface area and the availability of more adsorption sites. At biosorbent dosage greater than $0.5 \mathrm{~g}$ the surface AY 17 concentration and the solution AY 17 concentration come to equilibrium with each other.

\subsection{Effect of initial dye concentration}

The effect of initial dye concentration on the adsorption of dye was investigated and shown in Fig. 5. It provides an important driving force to overcome all mass transfer resistances of the dye between the aqueous and solid phases, thus increases the uptake. The equilibrium uptake values increased from 1.8 to $38.5 \mathrm{mg} / \mathrm{g}$ with increasing initial dye concentration from 25 to $600 \mathrm{mg} / \mathrm{L}$ as a result of the increase in the driving force. However, AY 17 removal yield increased from 90 to $94 \%$ from 25 to $150 \mathrm{mg} / \mathrm{L}$ concentration, and then started to decrease from 94 to $77 \%$ for initial dye concentration of 175 to $600 \mathrm{mg} / \mathrm{L}$. At lower dye concentrations solute concentrations to biosorbent sites ratio is higher, which cause an increase in color removal (Aksu \& Kabasakal, 2004). At higher concentrations, lower adsorption yield is due to the saturation of adsorption sites.

\subsection{Effect of contact time}

The effect of contact time on adsorption of AY 17 by SBG at $\mathrm{Co}=100 \mathrm{mg} / \mathrm{L}$ for adsorbent dosage $0.5 \mathrm{~g}$ is presented in Fig. 6. It can be observed from the figure that rapid adsorption of dye has taken place in the first $10 \mathrm{~min}$ and, thereafter, the rate of adsorption decreased gradually and reached equilibrium in about $40 \mathrm{~min}$. around $94 \%$ of AY 17 removal was obtained in about $40 \mathrm{~min}$. This may be due to strong attractive forces between the dye molecules and the adsorbent. Fast diffusion on the external surface was followed by fast pore diffusion into the intra particle matrix to attain rapid equilibrium (Ho \& Chiang, 2001). Further increase in contact time showed that there is no significant increase in the removal of AY 17 by SBG, so further experiments were conducted for 40 min contact time only.

\subsection{Kinetic modelling}

In order to investigate the biosorption processes of AY 17 on the SBG, pseudo-first order and pseudo-second order kinetic models were used.

\subsubsection{Pseudo-first-order model}

The pseudo-first-order equation is given as:

$$
d q_{t} / d t=k_{f}\left(q_{e}-q_{t}\right)
$$


where $q_{t}$ is the amount of adsorbate adsorbed at time $t(\mathrm{mg} / \mathrm{g}), q_{e}$ is the adsorption capacity at equilibrium (mg/g), $k_{f}$ is the pseudo-first-order rate constant $\left(\mathrm{min}^{-1}\right)$, and $t$ is the contact time (min). The integration of Eq. (1) With the initial condition, $q_{t}=0$ at $t=0$ leads to:

$\log \left(q_{e}-q_{t}\right)=\log q_{e}-\frac{k_{f}}{2.303} t$

The values of adsorption rate constant $\left(k_{f}\right)$ for AY 17 adsorption on SBG were determined from the plot of log $\left(q_{e}-q_{t}\right)$ against $t$ (not shown here). These values are given in Table 1.

3.6.2 Pseudo-second-order model

The pseudo-second-order model is given as:

$$
\frac{d q}{d t}=k_{s}\left(q_{e}-q_{t}\right)^{2}
$$

Where $\mathrm{k}_{\mathrm{s}}$ is the pseudo-second-order rate constant $(\mathrm{g} / \mathrm{mg} \mathrm{min}), q_{e}$ is the amount of dye adsorbed at equilibrium (mg/g), and $q_{t}$ is the amount of dye adsorbed at time $t(\mathrm{mg} / \mathrm{g})$. Integrating Eq. (3) for the boundary conditions $t=0$ to $t=t$ and $q_{t}$ $=0$ to $q_{t}=q_{t}$ gives

$q_{t}=\frac{q_{e}{ }^{2} k_{s} t}{1+q_{e} k_{s} t}$

Eq. (4) is the integrated rate law for a second-order reaction (Ho, 2006) and can be rearranged to obtain

$$
q_{t}=\frac{t}{\frac{1}{k_{s} q_{e}^{2}}+\frac{t}{q_{e}}}
$$

This has a linear form of

$$
\frac{t}{q_{t}}=\frac{1}{k_{s} q_{e}{ }^{2}}+\frac{1}{q_{e}} t
$$

The initial adsorption rate, $h(\mathrm{mg} / \mathrm{g} \mathrm{min})$ is defined as:

$$
h=k_{s} q_{e}^{2}
$$

The rate parameters $k_{s}$ and $q_{e}$ can be directly obtained from the intercept and slope of the plot $\left(t / q_{t}\right)$ against $t$ (Fig. 7). Values of $k_{s,} q_{s, h}$ and correlation coefficient $\mathrm{R}^{2}$ are listed in Table 2 . The calculated correlation coefficients are closer to unity for pseudo-second-order kinetics than that for the pseudo-first-order kinetic model. Therefore, the sorption can be approximated more appropriately by the pseudo-second-order kinetic model for the biosorption of AY 17 by SBG.

\subsection{Equilibrium modelling}

The equilibrium sorption isotherm is fundamentally important in the design of adsorption system. Equilibrium studies in adsorption gives the capacity of the sorbent. Equilibrium relationships between sorbent and sorbate are described by adsorption isotherms, usually the ratio between the quantity sorbed and that remaining in the solution at a fixed temperature at equilibrium (Ho et $a l ., 2002$ ). Freundlich and Langmuir isotherm constants were determined from the plots of $\ln q_{e}$ versus $\ln \mathrm{C}_{\mathrm{e}}$ (Fig.8) and $\mathrm{C}_{\mathrm{e}} / q_{e}$ versus $\mathrm{Ce}$ (not shown here) respectively, at 303, 313, $323 \mathrm{~K}$. It was found that the Freundlich isotherm best represents the equilibrium adsorption of AY 17 on SBG. The isotherm constants and the correlation coefficient, $\mathrm{R}^{2}$ with the experimental data is given in Table 3 . As seen from Table 3 , the parameter $\mathrm{K}_{\mathrm{F}}$ (Freundlich constant) related to the adsorption density increased with a decrease in temperature. This was consistent with the experimental observation; it also indicates that $n$ (intensity of adsorption) is greater than unity, indicating that the dye is favourably adsorbed by biomass at all temperatures studied.

\section{Conclusions}

The capability of the use of spent brewery grains for the removal of Acid Yellow dye was examined, including equilibrium and kinetic studies. Experiments were performed as a function of initial solution $\mathrm{pH}$, temperature, initial dye concentration, biosorbent dosage and contact time. The solution $\mathrm{pH}$, temperature and initial dye concentration played a significant role in affecting the capacity of biosorbent. The further increase in $\mathrm{pH}$ over 2.0, temperature over $303 \mathrm{~K}$ and initial dye concentration of $150 \mathrm{mg} / \mathrm{L}$ led to a reduction of the biosorption capacity of the biomass. Optimum 
sorbent dosage was $0.5 \mathrm{~g} / \mathrm{L}$ of solution. The equilibrium between the adsorbate in the solution and on the adsorbent surface was practically achieved in $40 \mathrm{~min}$. Biosorption kinetics was found to follow pseudo-second-order rate expression. Equilibrium biosorption data for AY 17 on SBG were best represented by Freundlich isotherm. The present study concludes that spent brewery grains could be employed as a low-cost and ecofriendly biosorbent as an alternative to the current expensive methods of removing dyes from textile effluents. The spent biosorbent SBG may be dried and incinerated.

\section{Acknowledgements}

The financial support for this investigation given by Council of Scientific and Industrial Research (CSIR), Ministry of Human Resources Development, New Delhi, India under the grant CSIR Lr. No. 9/468(371)/2007-EMR-1 dated 30.03.2007 is gratefully acknowledged.

\section{References}

Aksu, Z. \& Kabasakal, E. (2004). Batch adsorption of 2, 4-dichlorophenoxy-acetic acid (2, 4-D) from aqueous solution by granular activated carbon. Sep. Purif. Technol., 35, 223-240.

Asfour, H.M., Fadeli, O.A., Nasser, M.M. \& El-Geundi, M.S. (1985). Colour removal from textile effluents using hardwood sawdust as adsorbent. J. Chem. Technol. Biotechnol. 35, 21-27.

Chiou, M.S. \& Li, H.Y. (2002). Equilibrium and kinetic modeling of adsorption of reactive dye on cross-linked chitosan beads J.Hazardous Matter., B 93, 233-248.

Crini, G. (2006). Non-conventional low-cost adsorbents for dye removal: A review. Bioresour. Technol., 97, 1061-1085.

Deo, N. \& Ali, M. (1993). Adsorption by a new low cost material Congo red 2.Ind. J. Environ. Protect. 13, 496-508.

Fu, Y. \& Viraraghavan, T. (2001) Fungal decolorization of dye wastewaters: a review.. Bioresour. Technol, 79, 251-262.

Ho, Y.S. \& Chiang, C.C. (2001). Sorption studies of acid dye by mixed sorbents. Adsorption-Journal of the International Adsorption Society, 7, 139-147.

Ho, Y.S., Huang, C.T. \& Huang, H.W. (2002). Equilibrium sorption isotherm for metal ions on tree fern. Process Biochem, 37 (12), 1421-1430.

Ho, Y.S. (2006). Review of second-order models for adsorption systems. J.Hazardous Mater, 136, 681-689.

Juang, R.S., Tseng, R.K.L., Wu, F.C. \& Lee, S.H. (1997). Adsorption behaviour of reactive dyes from aqueous solution on chitosan. J. Chem. Technol., 70, 391-399.

Khare, S.K., Panday, K., Srivastava, R.M., \& Singh, V.N. (1987). Removal of victoria blue from aqueous solution by fly ash. J. Chem. Technol. Biotechnol, 38, 99-104.

Khattri, S.D. \& Singh, M.K. (1998). Colour removal from aqueous solutions by Adsorption. Ind. J. Chem. Technol., 5, 230-234.

Ko, D.C.K., Porter, J.F. \& McKay, G. (2000). Optimized correlations for the fixed bed adsorption of metal ions on bone char. Chem. Eng. Sci., 55, 5819-5829.

Lee, C.K. \& Low, K.S. (1997). Quaternized rice husk as sorbent for reactive dyes. Bioresour. Technol. 61, 121-125.

McKay, G., Allen, S.J., McConvey, I.F. \& Otterburn, M.S. (1981). Transport processes in the sorption of colored ions by peat particles. J. Colloid Interface Sci., 80, 323-339.

McKay, G., Blair, H.S. \& Gardner, J.S. (1983). Rate studies for the adsorption of dyestuffs on chitin. J. Colloid Interface Sci, 95, 108-119.

McKay, G. (1984). Analytical solution using a pore diffusion model for a pseudo irreversible isotherm for the adsorption of basic dye on silica. J.AIChE, 30, 692-697.

McKay, G., Geundi, E.I. \& Nasser, M.M. (1987). Equilibrium studies during the removal of dyestuff's from aqueous solutions using bagasse pith. Water Resour, 21, 1513-1520.

Namasivayam, C. \& Kavitha, D. (2002). Removal of Congo Red from water by adsorption on to activated carbon prepared from coir pith, an agricultural solid waste. Dyes and pigments, 54, 47-58.

Nassar, M.M. (1999). Interparticle diffusion of basic red and basic yellow dyes on palm fruit bunch. Water Sci. Technol,. 40, 133-139.

Ramakrishna, K.R. \& Viraraghavan, T. (1997). Use of slag for dye removal. Waste Manage., 17, 483-488. 
Waranusantigul, P., Pokethitiyook, P., Kruatrachue, M. \& Upatham, E.S. (2003). Kinetics of basic dye (methylene blue) biosorption by giant duckweed (Spirodela polyrrhiza). Environ. Pollut, 125, 385-392.

Table 1. Kinetic parameters for the removal of AY 17 by SBG, Pseudo-first-order model

\begin{tabular}{cccc}
\hline $\mathrm{C}_{\mathrm{o}}(\mathrm{mg} / \mathrm{L})$ & $\mathrm{q}_{\mathrm{e}}(\mathrm{mg} / \mathrm{g})$ & $\mathrm{k}_{\mathrm{f}}(1 / \mathrm{min})$ & $\mathrm{R}^{2}$ \\
\hline 100 & 0.904 & 0.066 & 0.9278 \\
150 & 0.904 & 0.066 & 0.9278 \\
200 & 0.904 & 0.066 & 0.9278 \\
300 & 3.773 & 0.283 & 0.7987 \\
\hline
\end{tabular}

Table 2. Kinetic parameters for the removal of AY 17 by SBG, Pseudo-second-order model

\begin{tabular}{ccccc}
\hline $\mathrm{C}_{\mathrm{o}}(\mathrm{mg} / \mathrm{L})$ & $\mathrm{q}_{\mathrm{e}}(\mathrm{mg} / \mathrm{g})$ & $\mathrm{k}_{\mathrm{s}}(\mathrm{g} / \mathrm{mg} \min )$ & $\mathrm{h}(\mathrm{mg} / \mathrm{g}$ min $)$ & $\mathrm{R}^{2}$ \\
\hline 100 & 7.911 & 0.181 & 11.335 & 0.9999 \\
150 & 12.077 & 0.185 & 27.086 & 1 \\
200 & 16.233 & 0.187 & 49.491 & 1 \\
300 & 24.570 & 0.190 & 114.942 & 1 \\
\hline
\end{tabular}

Table 3. Freundlich isotherm constants for biosorption of AY 17 onto SBG

\begin{tabular}{cccc}
\hline $\mathrm{T}(\mathrm{K})$ & $\mathrm{K}_{\mathrm{F}}(\mathrm{mg} / \mathrm{g})(\mathrm{L} / \mathrm{mg})^{\mathrm{n}}$ & $\mathrm{n}$ & $\mathrm{R}^{2}$ \\
\hline 303 & 1.934 & 1.534 & 0.8937 \\
313 & 0.828 & 1.195 & 0.8213 \\
323 & 0.474 & 1.073 & 0.7465 \\
\hline
\end{tabular}



Figure 1. Chemical structure of Acid yellow 17 




Figure 2. The effect of initial $\mathrm{pH}$ of dye solution



Figure 3. The Effect of temperature 




Figure 4. Effect of biosorbent dosage



Figure 5. Effect of initial dye concentration

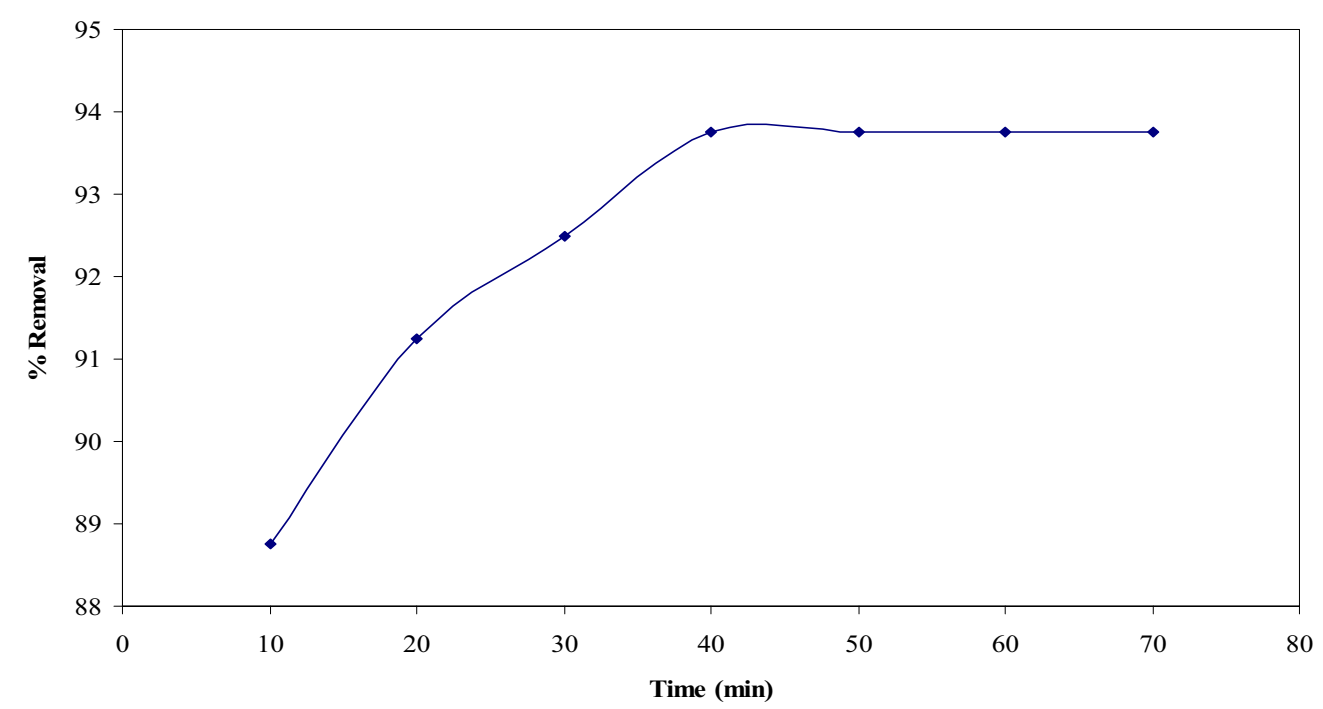

Figure 6. Effect of contact time 


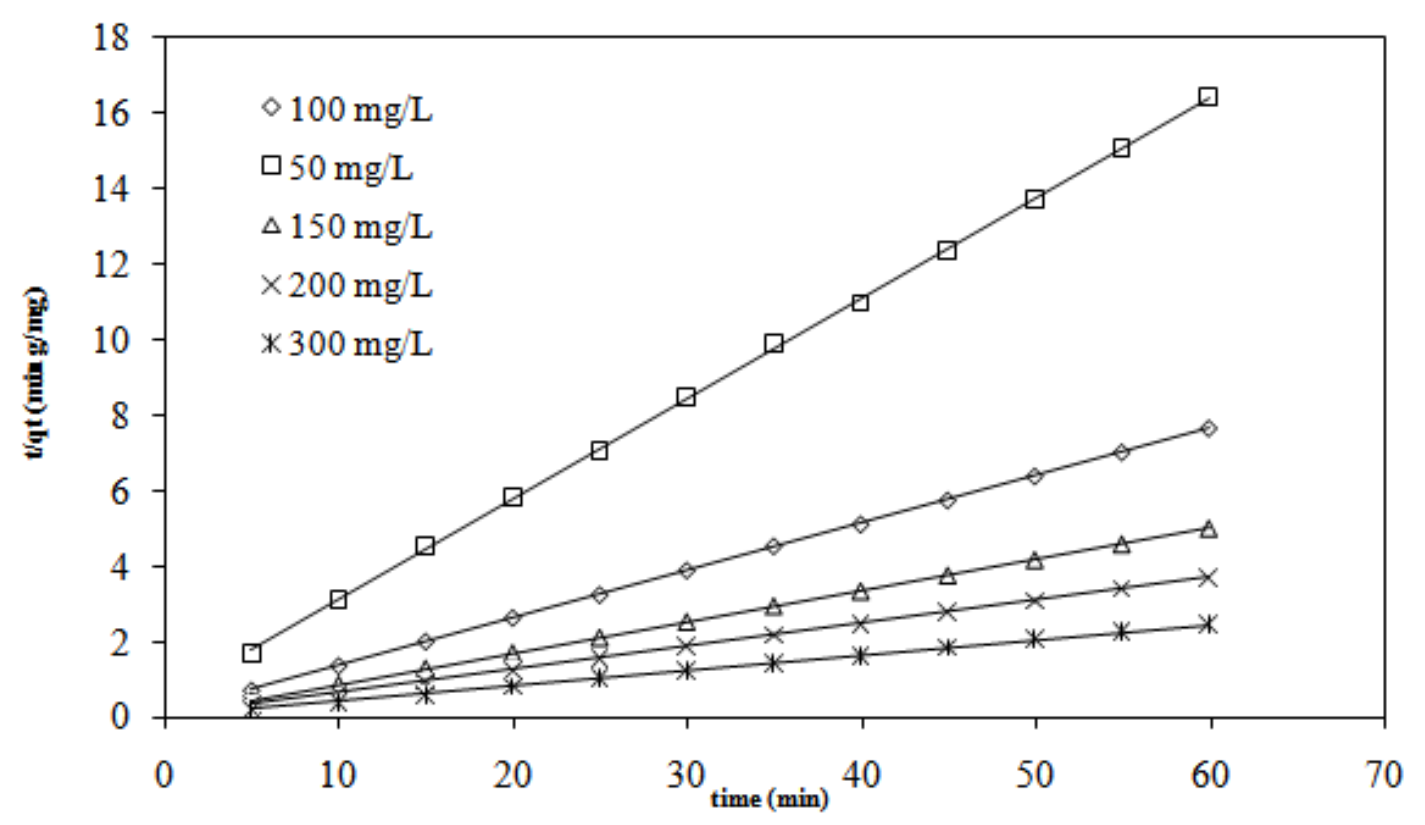

Figure 7. Pseudo-second-order kinetic plot for the removal of AY 17



Figure 8. Freundlich isotherm 